\title{
Investigating violence against Accredited Social Health Activists (ASHAs): a mixed methods study from rural North Karnataka, India
}

\author{
Lavanya Rao ${ }^{1}$, Ravi Prakash ${ }^{2}$, Prathibha Rai ${ }^{1}$, Mallika Tharakan ${ }^{1}$, Kavitha DL ${ }^{1}$, Arin Kar ${ }^{1}$, Mohan HL $^{1}$, Krishnamurthy \\ Jayanna ${ }^{3}$ \\ ${ }^{1}$ Karnataka Health Promotion Trust (KHPT), Bangalore, India, ${ }^{2}$ Karnataka Health Promotion Trust (KHPT), Bangalore, India; University of Manitoba, \\ Winnipeg, Canada, ${ }^{3}$ Karnataka Health Promotion Trust (KHPT), Bangalore, India; M.S. Ramaiah University of Applied Sciences, Bangalore, India \\ Keywords: accredited social health activist, violence against women, gender-based violence, india, family planning \\ https://doi.org/10.29392/001c.24351
}

\section{Journal of Global Health Reports}

Vol. 5, 2021

\begin{abstract}
Background
Accredited Social Health Activists (ASHAs) are female community health workers who primarily work to improve local reproductive, maternal, neonatal, and child health across India. As ASHAs often hail from patriarchal environments and are positioned at the bottom of the healthcare hierarchy, they are vulnerable to experiencing different forms of violence from the various individuals that they interact with. There is a gap in knowledge about the violence ASHAs experience. The purpose of this study was to assess the working condition of ASHAs, the extent and types of violence they experienced, and the corresponding perpetrators of this violence in two districts of Northern Karnataka.
\end{abstract}

\section{Methods}

Using a mixed methods approach, we first surveyed 396 ASHAs to characterize their experiences of violence. We then conducted in-depth interviews with 16 ASHAs to elaborate on survey findings. Data was analyzed using quantitative prevalence statistics and qualitative thematic analysis.

\section{Results}

The majority of ASHAs reported economic (88\%) or emotional violence (73\%), while many ASHAs reported sexual (32\%) or physical violence (26\%). ASHAs reported high levels of economic violence from their beneficiaries and their beneficiaries' families (64\%), emotional violence from their co-workers (44\%), and physical and sexual violence from their husbands (17\% and 12\% respectively). Mixed methods findings revealed that violence was often rooted from their low positioning on the healthcare hierarchy, a lack of respect from community members, and limited autonomy at home.

\section{Conclusions}

Evidence from this study suggests that violence perpetrated against ASHAs is highly prevalent, diverse in forms, and often arises from the ASHA's immediate circles. Interventions aiming to decrease violence against ASHA workers requires multi-level approach, with collaborative components empowering ASHAs, sensitizing ASHA families and co-workers, implementing regulations at the health facility level, and increasing community-wide respect for ASHAs and their role in the health care.

In efforts to expand accessible health coverage to rural areas, India enacted the National Rural Health Mission (NRHM) in 2005. One significant component of the NRHM has been the Accredited Social Health Activist (ASHA) program, consisting of ASHAs, or female community health workers (CHWs) working to improve reproductive, maternal, neonatal, and child health across India. ${ }^{1}$ The ASHA program is thought to be the NRHM's most visible and important mechanism for community outreach. It is likely the world's largest CHW program with about 1 ASHA per 1000 individuals in India. ${ }^{2}$
The ASHA program presents a vital opportunity to improve public health services across India through facilitating community participation in public health programs, decreasing pressure on the Indian health system, and promoting local access to healthcare. ${ }^{3-6}$ ASHAs facilitate family planning, antenatal and postnatal, and early child health services for their beneficiaries. ASHAs work alongside Anganwadi workers and Junior Health Assistants (JHA), two other groups of Indian CHWs that also promote women and children's health. ${ }^{4,7,8}$ Additionally, ASHAs work with nurses and medical doctors in primary health centers 
(PHCs), where they often escort women to primary health centers for childbirth. ${ }^{9}$ Notably, since early 2020, ASHA workers have been in the forefront of the COVID-19 pandemic, spreading awareness about prevention and control measures, documenting COVID symptoms, and addressing misinformation about the virus. ${ }^{10-13}$

As ASHAs often hail from patriarchal environments and operate within an existing village power structure ${ }^{14}$ they are vulnerable to experiencing violence from the various individuals that they interact with. The World Health Organization, International Labor Office, International Council of Nurses, and Public Services International have all stressed the need for workplace violence to be addressed within healthcare settings. ${ }^{15}$ Although the media portrays expatriate health workers as the primary victims of violence, local health workers are disproportionately affected by violence at higher rates. 16

Prior research has found that ASHAs face significant challenges in carrying out their work. ${ }^{17}$ ASHAs have expressed worries related to their limited renumeration $3,14,18$ and familial pressure against working due to their low or delayed pay. ${ }^{19}$ While research has evaluated structural challenges in the ASHA program, 1,3-5,7,8 such as the hierarchical structure of the health system ${ }^{7}$ and limited community sensitization of the ASHA program, ${ }^{5}$ first-person accounts of violence perpetrated against ASHAs are limited. As the world's largest community health worker program and as an integral component of promoting health access across India, it is vital to understand mistreatment ASHAs face. Understanding first-hand reports and narratives of violence experienced by ASHAs will help to devise solutions that can promote a better work environment for them. The study assessed the working experiences of ASHAs, including the extent and types of violence experienced by ASHAs, and investigated the corresponding perpetrators of this violence in two districts of Northern Karnataka.

\section{METHODS}

This study employed a mixed methods design, connecting themes across the survey and interview instruments to facilitate synergy of quantitative and qualitative data. The quantitative survey aimed to estimate the forms, levels, and key perpetrators of violence experienced by ASHAs, and the qualitative interviews explored the details surrounding these key perpetrators.

From February-March 2016, we conducted cross-sectional surveys and qualitative interviews with ASHA workers. Quantitative data was collected across Bagalkot and Koppal, two districts of Northern Karnataka, and qualitative data was collected in Bagalkot. The districts with quantitative data collection were chosen to include districts with large socio-economically disadvantaged populations and with accessible health systems to conduct research within. The district for the qualitative data collection was selected due to a strong relationship with the local health system.

The sample size for the survey was calculated based on the prevalence of physical or sexual violence among ASHAs, which was estimated at $50 \%$. Since estimates for violence against ASHAs have not been previously studied, the prevalence was set at $50 \%$ because the estimated sample size is largest when the unknown population proportion is 0.5 . The estimated sample size for this study was calculated to be 384 , rounded to 400 , with a $95 \%$ confidence interval and $5 \%$ margin of error.

Multi-stage stratified-random sampling was employed for the survey sample selection. 50\% of the taluks (subdistricts) in Bagalkot and Koppal were randomly selected, and amongst these taluks, 50\% of PHCs in which ASHAs work were selected. A complete list of ASHAs working in these primary health centers was obtained. ASHAs were stratified by caste and years of work experience and were then randomly selected to participate in the study from the stratified list. Of the 400 ASHAs contacted for the survey, 396 ASHAs completed the survey (99\% response rate). The high response rate is in part due to the strong relationship that Karnataka Health Promotion Trust (KHPT) has with ASHA workers from this region. KHPT conducts local capacity building workshops with community health workers, and thus has a strong local network with ASHAs. For ASHAs that did not respond to initial survey requests, local KHPT staff followed up through phone calls and text messages. This response rate is consistent with community participation in other KHPT research initiatives. ${ }^{20,21}$ ASHAs were delivered paper surveys by local KHPT staff and completed the paper surveys privately without interference from household members or healthcare colleagues. 16 different ASHAs were contacted to be interviewed, all of whom participated. Qualitative interview participants were chosen purposively based on those who had previously articulated having experienced violence to local KHPT staff.

Questions used to assess emotional, physical, and sexual violence in the quantitative survey were based on pre-validated surveys used in state and national studies, including India's Demographic Health Surveys (DHS). In this paper, we defined economic violence as limiting access to earnings, employment, and exclusion from financial decisionmaking. ${ }^{22}$ The questions used to assess economic violence were crafted through an examination of literature and from conversations with ASHA workers during initial field visits. The final survey instrument was pretested amongst ASHAs prior to official data collection.

Qualitative in-depth interviews were conducted in March 2016 after selected participants underwent a 2-day workshop in which the concepts of violence against women and women's empowerment were covered through mediums of conversation, art, and music. These workshops were devised to provide ASHAs a safe space to reflect upon their experiences. Post-workshop, each participant was interviewed through a semi-structured format about their experience as an ASHA worker and violence that they may or may not have faced. To account for the sensitivity of the interview topics, the interviewer was female.

The primary outcome of the study was prevalence of different forms of violence measured as a binary variable-yes if the ASHA experienced the form of violence in the 6 months preceding the survey and no if otherwise. Using DHS measurements, an ASHA was categorized to have experienced emotional violence if she had been humiliated in front of others, threatened, or insulted repeatedly, economic violence if anyone had forcefully taken her money, forced her to make bribes, or showed hostility towards her 
for earning money, physical violence if anyone pushed, shook, slapped, shoved, hit, kicked, choked, burned, used a weapon, or threatened to use a weapon on her, and sexual violence if anyone unsolicitedly spoke to her, looked at, touched, teased her in a sexual way, physically forced sex, or forced her to do something sexual that she found degrading or humiliating.

The quantitative data was computerized in a database developed using CSPro $^{23}$ with built-in consistency checks, and was then exported to STATA $14.0 .^{24}$ The qualitative interviews were first transcribed verbatim in Kannada, and then translated into English by an outside independent consultant. All transcripts were reviewed for accuracy and completeness. The transcripts were next imported into the qualitative software Dedoose. ${ }^{25}$ A coding scheme was developed based on the interview guide, field notes, preliminary quantitative results, and available literature. New codes and categories that emerged during the analysis were included in the coding process. Thematic saturation was observed, and extensive memos were written while coding, which provided space to compare the data across different forms of violence and to draw interpretations. This study obtained ethical approval from the Institutional Review Board of St. John's Medical College, Bangalore, India. All participants gave written informed consent in Kannada, Karnataka's local language. This study was supported from Fulbright fellowship funds, sponsored by the United StatesIndia Educational Foundation.

\section{RESULTS}

Of the 400 ASHAs contacted, 396 responded, consented to, and completed the in-person quantitative survey (Bagalkot $(n=200)$, Koppal $(n=196))$. The mean age of the respondents was 34 years and the majority of ASHAs had completed education up to or beyond $7^{\text {th }}$ standard. Most ASHAs were currently married (69\%), with $78 \%$ of ASHAs having been married at or before the age of 18 . The median number of years having worked as an ASHA was 7. Nearly half (45\%) of ASHAs were the primary earning members and $42 \%$ were the primary decision makers of their families. The majority of ASHAs (65\%) had a monthly income of less than $5000 \mathrm{ru}-$ pees/month (about \$68 USD) (Table 1).

Virtually all (94\%) reported facing some type of violence in the 6 months preceding the survey. Most ASHAs had faced economic (88\%) or emotional violence (73\%), while many ASHAs had faced physical (26\%) or sexual violence (32\%). About $15 \%$ of ASHAs had faced all forms of violence probed for in the survey; economic, emotional, physical, and sexual violence (Table 2 ).

ASHAs faced particularly high levels of economic and emotional violence from the families of the female beneficiaries they served (60\% and $26 \%$ respectively) and high physical and sexual violence from their husbands (13\% and $10 \%$ respectively). PHC Doctors and Staff Nurses were also reported to have inflicted high amounts of economic and emotional violence upon ASHAs (Table 3).

\section{FAMILIES OF BENEFICIARIES}

There were numerous narrations of economic and emo-

tional violence faced by ASHAs in the qualitative interviews. During interviews, ASHAs expressed that they received unwarranted blame from the families of beneficiaries for reasons that were beyond their responsibilities. In most interviews, ASHAs stressed that they were disrespected by the families of beneficiaries, often due to their positioning as women challenging traditional power dynamics and household practices.

\begin{abstract}
'It will take a full day for a pregnant woman to complete checkups. If the pregnant woman comes home late, we [the ASHAs] will be shouted at by the patient's family members. Some families will shout, "Hey ASHA, what have you done, when did you take her for a checkup, how can you come back so late?"' [ASHA \#5]
\end{abstract}

As seen above, the ASHA was held responsible for the beneficiary's late return, despite this being out of the ASHA's control. Similarly, a different ASHA spoke about blame she received from a beneficiary's husband for the fault of a different community health worker.
'When a pregnant patient is taken to the hospital, she will be given monetary compensation. Without knowing that a Junior Health Assistant stole the compensation, the pa- tient's husband screamed that I took the money. He used to come to my house to shout at me. He was so angry that he tried to physically abuse me.' [ASHA \#4]

\section{HEALTHCARE STAFF}

Quantitative findings revealed that a lot of economic and emotional violence were perpetrated through the PHC Staff Nurse (32\% and $11 \%$ respectively) and the PHC Doctor (19\% and $16 \%$ respectively). These findings corroborated the experiences shared by ASHAs in qualitative interviews.
'The [PHC] Doctor shouted that this was his hospital, and said, "Why do you come here, what is your work, who are you ASHA, what is your value, how much they even pay you?' [ASHA \#6]

ASHAs expressed that their co-workers who had higher positions felt entitled to make unjustified demands from them. A few ASHAs expressed that PHC Staff Nurses and Doctors had forced them to make monetary bribes.
'When there is a delivery, they [the Staff Nurse or PHC Doctor] will demand 500-1000 rupees from patients for themselves to keep, and will force us ASHAs to collect the bribe.' [ASHA \#3]

Since the ASHA is the intermediary between patients and a senior healthcare staff, she is exploited into requesting money from patients on behalf of those above her.

Findings revealed that ASHA not only face different forms of violence by their senior colleagues, but also from their fellow community health workers-24\% of ASHAs reported economic violence and $26 \%$ of ASHAs reported emotional violence from other community health workers in the quantitative survey.

'Even if we [ASHAs] do our work efficiently, the Female JHAs create mistakes in our work. Even after working proficiently, the Female JHAs tell us that we didn't work at all and purposely delay our payments.' [ASHA \#9] 
Table 1. Profile of ASHAs who participated in quantitative study

\begin{tabular}{|c|c|c|c|}
\hline \multicolumn{2}{|l|}{ General characteristics } & $\%$ & $N(396)$ \\
\hline \multicolumn{2}{|l|}{ Age (mean $\pm S D)$} & $34 \pm 5.74$ & 396 \\
\hline \multirow[t]{3}{*}{ Highest grade of education completed } & $<7$ & 9 & 35 \\
\hline & $7-9$ & 44 & 176 \\
\hline & $10+$ & 47 & 185 \\
\hline \multirow[t]{2}{*}{ Religion } & Hindu & 93 & 369 \\
\hline & Other & 7 & 27 \\
\hline \multirow[t]{2}{*}{ Caste } & $\begin{array}{l}\text { Scheduled caste, scheduled tribe, } \\
\text { other backward class }\end{array}$ & 32 & 128 \\
\hline & Other & 68 & 268 \\
\hline \multicolumn{4}{|l|}{ Marital characteristics* } \\
\hline \multirow[t]{3}{*}{ Marital status } & Currently Married & 69 & 273 \\
\hline & Deserted/separated/divorced/other & 13 & 51 \\
\hline & Widowed & 18 & 72 \\
\hline \multirow[t]{3}{*}{ Age when married } & $<=15$ & 31 & 84 \\
\hline & $16-18$ & 47 & 129 \\
\hline & $>19$ & 23 & 62 \\
\hline \multirow{3}{*}{$\begin{array}{l}\text { Highest grade of education that } \\
\text { husband has completed }\end{array}$} & $<7$ & 37 & 101 \\
\hline & $7-9$ & 20 & 56 \\
\hline & $10+$ & 43 & 118 \\
\hline \multirow[t]{2}{*}{ Husband currently employed } & No & 5 & 14 \\
\hline & Yes & 95 & 259 \\
\hline \multicolumn{4}{|l|}{ Household characteristics } \\
\hline \multirow[t]{2}{*}{ Main earning member of household } & Other family member & 55 & 217 \\
\hline & ASHA & 45 & 179 \\
\hline \multirow[t]{2}{*}{ Primary decision maker of household } & Other family member & 58 & 228 \\
\hline & ASHA & 42 & 168 \\
\hline \multicolumn{2}{|c|}{ Number of people living in household (mean \pm SD) } & $5 \pm 2.63$ & 396 \\
\hline \multirow[t]{2}{*}{ Type of household } & Non-nuclear & 50 & 196 \\
\hline & Nuclear & 51 & 200 \\
\hline \multicolumn{2}{|l|}{ Number of children (mean \pm SD) } & $2 \pm 1.08$ & 396 \\
\hline \multirow[t]{4}{*}{ Child sex composition } & No child & 9 & 35 \\
\hline & Sons=Daughter & 24 & 93 \\
\hline & Sons>Daughter & 39 & 154 \\
\hline & Sons $<$ Daughter & 29 & 114 \\
\hline \multicolumn{4}{|l|}{ Work characteristics } \\
\hline \multicolumn{2}{|c|}{ Monthly household income (from all income sources) (rupees) (mean \pm SD) } & $\begin{array}{l}5818 \pm \\
6042.15\end{array}$ & 391 \\
\hline \multicolumn{2}{|l|}{ Years working as an ASHA (mean \pm SD) } & $7 \pm 1.36$ & 396 \\
\hline \multirow{2}{*}{$\begin{array}{l}\text { Engaged in employment other than } \\
\text { ASHA work }\end{array}$} & No & 65 & 258 \\
\hline & Yes & 35 & 138 \\
\hline \multirow[t]{2}{*}{ ASHA Union affiliation } & No & 32 & 128 \\
\hline & Yes & 68 & 268 \\
\hline
\end{tabular}

*Questions in this section pertain to currently married ASHAs

ASHA - Accredited Social Health Activists, SD - standard deviation.

During interviews, ASHAs also mentioned that they were repeatedly made fun of by other community health workers 
Table 2. ASHAs who experienced violence

\begin{tabular}{|l|c|c|}
\hline Type of violence & \%Experienced in the past 6 months [CI] & $\mathbf{N}(396)$ \\
\hline Any violence & $94[91.3-96.1]$ & 371 \\
\hline Economic violence & $88[84.9-91.3]$ & 349 \\
\hline Emotional violence & $73[68.9-77.6]$ & 290 \\
\hline Physical violence & $26[21.4-30.1]$ & 102 \\
\hline Sexual violence & $32[27.2-36.4]$ & 126 \\
\hline Both physical and sexual violence & $16[12.3-19.5]$ & 63 \\
\hline Severe physical or sexual violence* & $24[20.0-28.5]$ & 96 \\
\hline All types of violence & $15[11.8-19.0]$ & 61 \\
\hline No violence & $6.3[3.9-8.7]$ & 25 \\
\hline
\end{tabular}

*Severe physical or sexual violence was defined as a combination of experiencing both physical and sexual violence in high frequency over the past 6 months ASHA - Accredited Social Health Activists

Table 3. ASHAs who experienced violence by key perpetrators

\begin{tabular}{|l|l|c|c|}
\hline Forms of violence & Key Perpetrators & \% [CI] & $\mathrm{N}[396]$ \\
\hline Economic violence & Family of female beneficiary & $60[55.4-65.2]$ & 239 \\
\hline & PHC staff nurse & $32[27.7-37.2]$ & 128 \\
\hline & Other CHWs & $28[23.3-32.2]$ & 109 \\
\hline & Husband & $24[19.5-28.0]$ & 94 \\
\hline & Female beneficiary & $19[15.7-23.7]$ & 77 \\
\hline & PHC doctor & $19[15.4-23.4]$ & 76 \\
\hline & Other CHWs & $26[22.2-30.4]$ & 104 \\
\hline & Family of female beneficiary & $26[21.3-30.1]$ & 101 \\
\hline & Husband & $24[20.6-29.3]$ & 98 \\
\hline & PHC doctor & $16[12.2-19.6]$ & 62 \\
\hline & Female JHA & $11[8.4-14.9]$ & 45 \\
\hline & PHC Staff Nurse & $11[8.0-14.4]$ & 43 \\
\hline & Husband & $13[10.0-16.9]$ & 52 \\
\hline & ASHA's family* & $5[3.1-7.7]$ & 20 \\
\hline & Family of female beneficiary & $3[1.8-5.6]$ & $3[1.6-5.2]$ \\
\hline
\end{tabular}

*Does not include ASHA's husband

ASHAs - Accredited Social Health Activists, CHWs - community health worker, JHA - Junior Health Assistant, PHC - primary health care.

due to poor reading and writing skills. Similar to ASHAs experiences with the PHC Staff Nurse/Doctor, ASHAs emphasized that their relationships with other community health workers were rooted in power dynamics resulting from ASHAs being on the bottom of the healthcare hierarchy.

\section{ASHA’S HUSBAND}

Perpetration of violence by the ASHA's husband was evident in the quantitative survey. About one-fourth of ASHAs re- ported economic and emotional violence from their husbands. Many ASHAs conveyed that they had limited control over their work earnings and were expected to give their money to their husbands as soon as they were paid. Such situations were particularly mentioned amongst ASHAs whose husbands were either not earning or earning little income.

'My husband takes all my money and spends it. He doesn't even give me 500 rupees for having worked throughout the month.' [ASHA \#11] 
Numerous ASHAs articulated that they had little autonomy over how they spent their time at home. Often, their husbands reacted violently over the mobility that the job allowed them and the decreased time ASHAs spent on housework.

\section{I...If I leave the house for work, he would say, "Who will take care of the household work and other duties?"... Re- cently, he has forced me to stay at home and not leave the house to work.' [ASHA \#13]}

The work of ASHAs involves catering to the needs of pregnant women, and sometimes these needs come at unexpected times. If a woman has late-night maternal complications, typically the ASHA is expected to assist her to and from the hospital. Many ASHAs expressed that their husbands violently disapproved when the ASHA came home late from work.

'I returned home at 10:30pm at night. There were arguments as to why I came home late. He used abusive words and foul language and he started to shout saying, "What kind of bloody meeting did you have?" [ASHA \#4]

\section{DISCUSSION}

In this study, we found high prevalence of violence, with 94\% of ASHAs having experienced violence in the 6 months preceding the survey. The high levels of violence were contributed by economic violence (88\%), emotional violence (73\%), physical violence (26\%), and sexual violence (32\%). A large proportion of ASHAs faced economic violence from the families of their beneficiaries and healthcare co-workers, emotional violence from their healthcare co-workers and husbands, and physical and sexual violence from their own husbands.

Violence against ASHAs has been increasingly recognized across India. India's National Health Mission developed a training handbook for ASHAs called "Mobilizing for Action on Violence Against Women", with a page on "how to keep yourself safe”, encouraging avoiding walking alone and moving in groups after dark, amongst other suggestions. ${ }^{26}$ Additionally, in "Safety measures for ASHAs", the Indian Ministry of Health and Family Welfare recommended that health facilities create safe rooms for ASHAs to stay in overnight when they have accompanied patients to hospitals and recommended for grievance redressal systems to be strengthened. ${ }^{27}$ While important steps, increased efforts are needed. In summer of 2020, 600,000 ASHAs went on strike against their working conditions during the COVID-19 pandemic. ASHAs protested for higher and more timely wages and personal protective equipment to work. One ASHA recounted an experience in which a man became violent after she asked him for his recent travel history. The ASHA stated, "People scream at me, curse me and pressure me not to give all the details". ${ }^{26,28}$

In this study, we found that ASHAs were often blamed by their beneficiaries' families for situations beyond their control. ASHAs were held responsible when their beneficiaries came home late from the hospital, were inappropriately charged fees by other hospital staff, or were not compensated for giving birth in a hospital. As beneficiaries were community members, a lack of respect from the families of beneficiaries likely reflects a lack of respect from the community.

It is evident that a strong healthcare hierarchy exists within India's public health system, ${ }^{29}$ and as ASHAs are positioned at the bottom of the healthcare ladder, they thus have limited authority to challenge those above them. ASHAs mentioned that they were intensely disrespected by higher-ranking co-workers, often resulting in different forms of violence. ASHAs reported several instances of being treated poorly by PHC Doctors, which has been observed to an extant in other studies. ${ }^{19}$ Even amongst ASHAs, JHAs, and Anganwadi workers, there were clear attempts of dominance between the different community health workers. These findings are consistent with other evidence suggesting that different cadres of community health workers often feel a sense of competition with one another, rather than cooperation. ${ }^{30}$ Though research has acknowledged that the hierarchical healthcare structure has negative implications for the ASHA program, ${ }^{3}$ this study details the violence that has emerged from this circumstance.

Being a woman engaged in the labor force in India comes with barriers, with one being that women often have expectations to complete a disproportionate share of housework and childcare. ${ }^{31}$ Evidence suggests that in certain countries, women's domestic burdens pose an impediment to economic participation, ${ }^{32}$ and research has found that with the ASHA program, gender roles limit ASHAs abilities to execute their professional roles. ${ }^{14,18}$ In this study, most ASHAs reported experiencing violence as a result of deviating from these gendered social expectations, which has thus far not been well documented. ASHAs expressed that they faced intense pushback from their families for working as ASHAs, ultimately resulting in violence.

As very high amounts of economic violence were recorded in this study, there is a need to address economic violence impacting ASHAs. Of the minimal research available on economic violence, evidence suggests that abusive partners prevent women from acquiring income by discouraging their economic autonomy ${ }^{22}$ and that women with husbands who contribute minimally to expenses may be more likely to experience spousal violence. ${ }^{33}$ In this study, many ASHAs conveyed that were expected to give their money to their husbands as soon as they were paid, especially if their husbands were either not earning or earning little income. Research has found that husband/familial support for ASHA-related work is correlated with a significantly higher number of households reached and clients accompanied for facility delivery, indicating that family support is vital in improving ASHA productivity and local health outcomes. ${ }^{34}$ It is crucial to understand the ways in which ASHA work effects family dynamics, to devise solutions so that ASHAs can go about their work with familial and spousal support, free from violence.

This study has a few limitations. As violence is a complex subject to comprehend and communicate, it is possible that some ASHAs may have underreported violence due to viewing violence as non-problematic, blaming themselves for violence, feeling ashamed, or fearing personal information spread. Though these factors were taken into consideration through quality rapport building and confidentiality assur- 
ance, it is possible that some ASHAs still did not share their full experiences.

From this study, it is not possible to determine how much of the reported domestic violence was solely a result of occupation-based factors. Work-related violence cannot be holistically addressed without acknowledging domestic violence, as much of the reported domestic violence drew from reports of ASHA work challenging traditional gender roles and household dynamics. By nature, ASHAs are defying household dynamics by being working women with jobs visible to the community. Through this research, we saw that the nature of ASHA work, including working late hours, threatened household dynamics. As ASHAs have extremely important responsibilities in promoting public health across India, any violence perpetrated against ASHAs likely serves as an impediment in an ASHA's ability to work, therefore posing a challenge to India's public health system. With so many ASHAs working across India, violence against ASHAs requires urgent attention to ensure better ASHA working conditions and to promote improved public health.

Lastly, while numerous ASHAs reported experiencing economic violence from their beneficiaries and their beneficiaries' families, our research did not explore this theme in detail during the qualitative interviews. However, this topic will be explored in future research.

\section{CONCLUSIONS}

Research on violence against ASHAs has not been thoroughly documented. In this study, we assessed the working experiences of ASHAs, including the extent and types of violence experienced by ASHAs, and the corresponding perpetrators of this violence in two districts of Northern Karnataka. Evidence from this study suggests that violence perpetrated against ASHAs is prevalent, diverse in forms, and arises from the ASHA's immediate circles. Findings of this study elucidate the issues that ASHAs face and highlight how surrounding social structures can enable a more supportive environment for ASHAs to work in. Interventions aiming to decrease violence against ASHAs may require a multi-level approach, with collaborative components operating at the individual, interpersonal, healthcare facility, and societal level. At the individual level, programs can empower ASHAs through reinforcing their legal rights, boosting their confidence, and equipping them with skills to recognize and report violence. At the interpersonal level, peer support networks amongst the different $\mathrm{CHW}$ groups can be established to build collective empowerment in supporting each other in addressing violence. Efforts can be made to sensitize ASHA families, including ASHA husbands, about the importance of ASHA work and the tasks associated with being an ASHA worker. At the healthcare fa- cility level, response mechanisms can be institutionalized that recognize different forms of violence against ASHAs, penalize perpetrators, and support ASHAs that have experienced violence. At the societal level, local community leaders can be sensitized to enable a supportive environment for ASHA workers to operate in. This in turn could promote community-wide respect for ASHAs, improving ASHA-beneficiary, ASHA-healthcare co-worker, and ASHA-family relationships.

\section{ACKNOWLEDGEMENTS}

We are grateful to the ASHA workers who shared their experiences with us. We thank Nagaraj Yarragunta, Girish KH, Sunitha BJ, Raj Kumar, Dr. Shajy Isac, Dr. Satyanarayana Ramanaik, Prakash Javalkar, and the other staff at the Karnataka Health Promotion Trust who provided technical inputs and helped to coordinate the study. We also thank Dr. Melinda Munos from the Johns Hopkins Bloomberg School of Public Health for her guidance in this paper. This study obtained ethical approval from the Institutional Review Board of St. John's Medical College, Bangalore, India.

\section{FUNDING}

This study was supported jointly from Fulbright fellowship funds, sponsored by the United States-India Educational Foundation, and Karnataka Health Promotion Trust.

\section{AUTHORSHIP CONTRIBUTIONS}

LR wrote the manuscript with input from all authors. PR and KDL planned and supervised data collection. RP and AK contributed to data analysis and research design. MHL, MT, AND KJ supervised the research. All authors provided critical feedback and helped shape the research, analysis, and manuscript.

\section{COMPETING INTERESTS}

The authors completed the Unified Competing Interest form at www.icmje.org/coi disclosure.pdf (available upon request from the corresponding author) and declare no conflicts of interest.

\section{CORRESPONDENCE TO:}

Lavanya Rao, Karnataka Health Promotion Trust (KHPT), Bangalore, India, lavanya.l.rao@gmail.com

Submitted: April 29, 2021 GMT, Accepted: May 16, 2021 GMT 


\section{REFERENCES}

1. Kapil U, Choudhury P. What is NRHM. Indian pediatrics. $2005 ; 42: 783-786$.

2. Report of the Working Group on National Rural Health Mission (NRHM) for the Twelfth Five Year Plan (2012-2017). Published online 2011.

3. Scott K, Shanker S. Tying their hands? Institutional obstacles to the success of the ASHA community health worker programme in rural north India. AIDS care. 2010;22(sup2):1606-1612.

4. National Health Systems Resource Centre. ASHA-which way forward? Evaluation of ASHA Programme. Published online 2011.

5. Joshi SR, George M. Healthcare through community participation: role of ASHAs. Economic and Political Weekly. Published online 2012:70-76.

6. Potty RS, Lakkappa MH, Kar A, Bidappa M, Manjappa RB, Jayanna K. Influence of integrated community-and facility-based interventions on select maternal and neonatal outcomes in Northern Karnataka, India: Lessons for implementation and measurement. Indian journal of public health. 2017;61(1):19.

7. National Health Mission. About Accredited Social Health Activist (ASHA). Published online 2021.

8. Fathima FN, Raju M, Varadharajan KS, Krishnamurthy A, Ananthkumar SR, Mony PK. Assessment of 'accredited social health activists'-a national community health volunteer scheme in Karnataka State, India. Journal of health, population, and nutrition. 2015;33(1):137.

9. Gopalan SS, Mohanty S, Das A. Assessing community health workers' performance motivation: a mixed-methods approach on India's Accredited Social Health Activists (ASHA) programme. BMJ open. $2012 ; 2(5)$.

10. Chakraborty S. At the tip of COVID-19 frontline. Telegraph India.

11. Awasthi P. The life of ASHA workers in the time of COVID-19. The Week.

12. Kapur M. Behind India's coronavirus vaccine plan is an army of poorly paid female health workers. Quartz India.
13. Kalita M, Borah G, Koch M. Role Of Accredited Social Health Activists (ASHA) Workers In Assam: An Analysis In The Context Of Coronavirus Disease Of 2019 (COVID-19) Pandemic. European Journal of Molecular \& Clinical Medicine. 2020;7(03):2020.

14. Saprii L, Richards E, Kokho P, Theobald S. Community health workers in rural India: analysing the opportunities and challenges Accredited Social Health Activists (ASHAs) face in realising their multiple roles. Human resources for health. 2015;13(1):1-13.

15. World Health Organization. Violence and Injury Prevention.

16. Stoddard A, Harmer A, Haver K. Aid Worker Security Report 2011 - Spotlight on security for national aid workers: Issues and perspectives. Published online 2011.

17. Ved R, Scott K, Gupta G, et al. How are gender inequalities facing India's one million ASHAs being addressed? Policy origins and adaptations for the world's largest all-female community health worker programme. Human Resources for Health. 2019;17(1):1-15.

18. Pala S, Kumar D, Jeyashree K, Singh A. Preliminary evaluation of the ASHA scheme in Naraingarh block, Haryana. The National medical journal of India. 2011;24(5):315-316.

19. Bhatia K. Performance-based incentives of the ASHA scheme: stakeholders' perspectives. Economic and Political Weekly. Published online 2014:145-151.

20. Jayanna K, Bradley J, Mony P, et al. Effectiveness of onsite nurse mentoring in improving quality of institutional births in the primary health centres of high priority districts of Karnataka, South India: a cluster randomized trial. PloS one. 2016;11(9):e0161957.

21. Jayanna K, Swaroop N, Kar A, et al. Designing a comprehensive Non-Communicable Diseases (NCD) programme for hypertension and diabetes at primary health care level: evidence and experience from urban Karnataka, South India. BMC public health. 2019;19(1):1-12.

22. Fawole OI. Economic violence to women and girls: Is it receiving the necessary attention? Trauma, Violence, \& Abuse. 2008;9(3):167-177.

23. U.S. Census Bureau. Census and Survey Processing System (CSPro). Published online 2021. 
24. StataCorp LP. Stata Statistical Software: Release 14. Published online 2015.

25. Dedoose Version 8.0.35, web application for managing, analyzing, and presenting qualitative and mixed method research data. SocioCultural Research Consultants, LLC. Published online 2018.

26. The National Health Mission. Mobilizing for Action on Violence Against Women; Hand Book for ASHA.

27. Government of India, Ministry of Health and Family Welfare. Safety measures for ASHAs. Published online 2016.

28. Srivastava S. India's Army of 600,000 VirusHunting Women Goes on Strike. Bloomberg.

29. Srinivasan K, Sharan R. Organization of Indian Health Bureaucracy and its Delivery System. Productivity, A Quarterly Journal of the National Productivity Council, India. 2006;46(4):477-486.
30. Javanparast S, Windle A, Freeman T, Baum F. Community health worker programs to improve healthcare access and equity: are they only relevant to low-and middle-income countries? International Journal of Health Policy and Management. 2018;7(10):943.

31. Ramu GN. Marital roles and power: Perceptions and reality in the urban setting. Journal of Comparative Family Studies. 1988;19(2):207-227.

32. Boserup E. Woman's Role in Economic Development. Earthscan; 2007.

33. Akamike IC, Uneke CJ, Uro-Chukwu HC, OkedoAlex IN, Chukwu OE. Predictors and facilitators of gender-based violence in sub-Saharan Africa: a rapid review. Journal of Global Health Reports. 2019;3.

34. Dehingia N, Shakya H, Chandurkar D, et al. Family support and community respect for community health workers and the association of these with CHW productivity and clinic health care utilization. Journal of Global Health Reports. 2020;4:e2020017. 